\title{
Lactogens protect rodent and human beta cells against glucolipotoxicity-induced cell death through Janus kinase-2 (JAK2)/signal transducer and activator of transcription-5 (STAT5) signalling
}

\author{
N. Guthalu Kondegowda • A. Mozar • C. Chin • \\ A. Otero • A. Garcia-Ocaña • R. C. Vasavada
}

Received: 20 September 2011 / Accepted: 11 January 2012 /Published online: 3 March 2012

(C) Springer-Verlag 2012

\begin{abstract}
Aims/hypothesis A leading cause of type 2 diabetes is a reduction in functional beta cell mass partly due to increased beta cell death, triggered by stressors such as glucolipotoxicity (GLT). This study evaluates the hypothesis that lactogens can protect beta cells against GLT and examines the mechanism behind the pro-survival effect.

Methods The effect of exogenous treatment or endogenous expression of lactogens on GLT-induced beta cell death was examined in INS-1 cells, and in rodent and human islets. The mechanism behind the pro-survival effect of lactogens was determined using an inhibitor, siRNAs, a dominant negative (DN) mutant, and Cre-lox-mediated gene deletion analysis.

Results Lactogens significantly protect INS-1 and primary rodent beta cells against GLT-induced cell death. The prosurvival effect of lactogens in rodent beta cells is mediated through activation of the Janus kinase-2 (JAK2)/signal transducer and activator of transcription-5 (STAT5) signalling pathway. Lactogen-induced increase in the anti-apoptotic B cell lymphoma-extra large (BCLXL) protein is required to mediate its pro-survival effects in both INS- 1 cells and primary rodent beta cells. Most importantly, lactogens significantly protect human beta cells against GLT-induced cell death, and their prosurvival effect is also mediated through the JAK2/STAT5 pathway. Conclusions/interpretation These studies, together with previous work, clearly demonstrate the pro-survival nature of lactogens and identify the JAK2/STAT5 pathway as an important mediator of this effect in both rodent and human beta
\end{abstract}

N. G. Kondegowda · A. Mozar · C. Chin · A. Otero •

A. Garcia-Ocaña $\cdot$ R. C. Vasavada $(\triangle)$

Division of Endocrinology, University of Pittsburgh,

200 Lothrop St, BST-E1157,

Pittsburgh, PA 15261, USA

e-mail: vasavada@pitt.edu cells. Future studies will determine the effectiveness of this peptide in vivo in the pathophysiology of type 2 diabetes.

Keywords BCLXL · Beta cell death · Glucolipotoxicity · Human beta cells · JAK2/STAT5 - Lactogens · Type 2 diabetes

$\begin{array}{ll}\text { Abbreviations } \\ \text { Adv } & \text { Adenovirus } \\ \text { BCLXL } & \text { B cell lymphoma-extra large } \\ \text { Ctrl } & \text { Control cDNA constructs } \\ \text { DEX } & \text { Dexamethasone } \\ \text { DN } & \text { Dominant negative DNA constructs } \\ \text { GFP } & \text { Green fluorescent protein } \\ \text { GLT } & \text { Glucolipotoxicity } \\ \text { HBS } & \text { Hank's buffered saline } \\ \text { hPL } & \text { Human placental lactogen } \\ \text { hPRL } & \text { Human prolactin } \\ \text { IIDP } & \text { Integrated Islet Distribution Program } \\ \text { JAK2 } & \text { Janus kinase-2 } \\ \text { mPL1 } & \text { Mouse placental lactogen 1 } \\ \text { MTT } & \text { 3-(4,5-Dimethylthiazol-2-yl)-2,5- } \\ & \text { diphenyltetrazolium bromide }\end{array}$

NIDDK National Institute of Diabetes and Digestive and Kidney Diseases

NIH National Institutes of Health

PI Propidium iodide

PL Placental lactogen

PRL Prolactin

PRL-R Prolactin receptor

oPRL Ovine prolactin

RIP Rat insulin promoter

SFM Serum-free medium

STAT5 Signal transducer and activator of transcription-5

STZ Streptozotocin 


\section{Introduction}

Type 2 diabetes is a metabolic disorder of fuel homoeostasis resulting from the interplay of environmental factors and genetic predisposition. It occurs when islet beta cells are unable to secrete adequate insulin to meet the extra demands of the body, mainly because of enhanced beta cell dysfunction and reduced beta cell mass. The reduction in functional pancreatic beta cell mass results partly from increased beta cell apoptosis [1-4], observed in several animal models of type 2 diabetes, such as $o b / o b$ and $d b / d b$ mice on a C57BL/KS background, transgenic rodents overexpressing human islet amyloid polypeptide, Zucker diabetic fatty rats, and Psammomys obesus [5-9]. Increased beta cell death is also observed in pancreatic sections from patients with type 2 diabetes relative to normal non-diabetic individuals $[10,11]$. Glucolipotoxicity (GLT), resulting from the hyperglycaemia and altered lipid metabolism that occurs from excessive nutrient intake, is believed to be a leading cause of beta cell death in type 2 diabetes [1-4, 12-14]. Therefore, finding ways to reduce GLT-mediated beta cell loss would have a significant bearing on patients with diabetes.

Prolactin (PRL) and placental lactogen (PL), members of the lactogenic family of peptide hormones, act through a common PRL receptor (PRL-R), which belongs to the class 1 cytokine receptor superfamily $[15,16]$. PRL-R is expressed in the beta cell of rodent and human islets [17, 18]. PRL-R signalling is critical for normal beta cell growth and function, as well as for the augmented beta cell function and expansion that happens during pregnancy, as demonstrated using whole body Prlr knockout mice [19, 20]. Several studies have shown that PRL and PL are beneficial for the beta cell, in that they enhance beta cell function, proliferation and survival [21-23]. We have previously generated transgenic mice that express mouse $P l 1$ (also known as Prl3dl) ( $\mathrm{mPll}$ ) in their beta cells using the rat insulin promoter (RIP). RIP-mPll transgenic mice are hypoglycaemic and hyperinsulinaemic, and display beta cell hyperplasia as a result of increased beta cell proliferation. These mice are also resistant to the diabetogenic and cytotoxic effects of the beta cell toxin streptozotocin (STZ) [24-26]. Studies from our group and others have found that lactogens improve beta cell survival against specific cell-death inducers, including STZ, cytokines, reactive oxygen species and the glucocorticoid, dexamethasone (DEX) [24-29]. However, whether lactogens protect beta cells against GLT, a likely cause of beta cell death in type 2 diabetes, is unknown.

This study demonstrates that, indeed, lactogens protect INS-1 and primary rodent beta cells against GLT-induced cell death. The pro-survival effect of lactogens in rodent beta cells is mediated through activation of the Janus kinase-2 (JAK2)/signal transducer and activator of transcription-5 (STAT5) signalling pathway and increase in production of
B cell lymphoma-extra large (BCLXL), an anti-apoptotic member of the BCL family. Furthermore, lactogens protect human beta cells against GLT, and this pro-survival effect is also mediated through JAK2/STAT5, identifying this signalling pathway as a potential therapeutic downstream target for type 2 diabetes.

\section{Methods}

Mouse strains These studies used 3-6-month-old male and female RIP-mPll transgenic mice bred onto a CD-1 background [24, 25], and 3-8-month-old male and female Bclxl lox/lox mice [30] kindly provided by L. Hennighausen (National Institutes of Health (NIH)/National Institute of Diabetes and Digestive and Kidney Diseases (NIDDK), Bethesda, MD, USA). All studies were performed with the approval of, and in accordance with, guidelines established by the University of Pittsburgh Institutional Animal Care and Use Committee, and principles of laboratory animal care were followed.

Mouse and human primary islet and rat insulinoma (INS-1) cell cultures Human islets were purchased through the Integrated Islet Distribution Program (IIDP) and JDRF basic science islet distribution programmes. Mouse islets were isolated, and cells were cultured from mouse and human islets, as described previously [26, 31]. Primary islet cell cultures were pre-treated with or without lactogens in serum-free medium (SFM) for $8 \mathrm{~h}$, and subsequently treated with SFM containing either $25 \mathrm{mmol} / \mathrm{l}$ glucose and $0.5 \mathrm{mmol} / 1$ palmitate (GLT) (Sigma Chemical, St Louis, MO, USA), or $5.5 \mathrm{mmol} / 1$ glucose and $0.5 \%$ BSA (Sigma) as a control, for 24-36 h. INS-1 cells [26] were pre-cultured in SFM with PRL, or vehicle as control, for $8 \mathrm{~h}$, and then treated with 0.25 or $0.5 \mathrm{mmol} / \mathrm{l}$ palmitate, (GLT) or $0.5 \%$ BSA as control for 12-16 h. GLT conditions refer to SFM containing $25 \mathrm{mmol} / 1$ glucose and $0.5 \mathrm{mmol} / 1$ palmitate for primary islet cell cultures, and 0.25 or $0.5 \mathrm{mmol} / \mathrm{l}$ palmitate for INS-1 cell cultures. Either $200 \mathrm{ng} / \mathrm{ml}$ of ovine PRL (oPRL; Sigma) was used for INS-1 cells and mouse islets, or $200 \mathrm{ng} / \mathrm{ml}$ of human PRL (hPRL; Sigma) or human PL (hPL; NIH/NIDDK) peptides were used for human islets. All lactogenic peptides were made in PBS with $0.1 \%$ BSA (vehicle). The $200 \mathrm{ng} / \mathrm{ml}$ dose of lactogens was chosen based on our previous research [26] and a current dose response study (Fig. 2e). Palmitate was preconjugated with fatty-acid-free BSA to generate a solution of $5 \%(\mathrm{wt} / \mathrm{vol})$ BSA, $5 \mathrm{mmol} / \mathrm{l}$ fatty acid in SFM [32]. For the pharmacological inhibitor study, cells were treated with $10 \mu \mathrm{mol} / 1$ of AG490 (Sigma), an inhibitor of JAK2, together with oPRL pre-treatment, or with an equal volume of the solvent, DMSO as control, or were left untreated. 
Adenovirus transduction Adenovirus (Adv) constructs containing cDNAs of dominant negative (DN) Stat5a [33], or encoding the proteins Cre recombinase or green fluorescent protein (GFP), were prepared and transduced at a multiplicity of infection of $80-100 \mathrm{pfu} / \mathrm{cell}$ as previously described [26, 31]. GLT-treatment (as described above) and immunostaining for CRE were performed $24 \mathrm{~h}$ after Adv transduction.

siRNA treatment INS-1 cells were transfected with $50 \mathrm{nmol} / 1$ of scrambled, Jak2 or Bclxl (also known as Bcl2ll) siRNA (Dharmacon, Chicago, IL, USA) as described previously [26] and then treated with palmitate as indicated above.

Cell death assays INS-1 cell viability was assessed using the 3-(4,5-dimethylthiazol-2-yl)-2,5-diphenyltetrazolium bromide (MTT) (Sigma) assay, or cell death quantified as percentage of cleaved caspase-3-positive cells after immunostaining [26]. Co-staining for insulin, TUNEL (Roche Applied Sciences, Indianapolis, IN, USA), and Hoechst33258 (Invitrogen, Eugene, OR, USA) [26] was used to measure beta cell death in mouse and human primary islet cell cultures.

RNA and protein analysis RNA isolated from islets and INS-1 cells was analysed by real time PCR [34], using primers for Bclxl 5'-TCCGAACGGTAAATGCCTAC-3' 5'GGTGTGAGTCCTGACCCTGT-3', actin, and Prlr 5'GAGAAGGGCAAGTCTGAAGAAC-3' 5'-GGGATGG CATTAGCCGCTC- $3^{\prime}$ that recognise the long form of the PRL-R. INS-1 and islet protein extracts $(20-40 \mu \mathrm{g})$ were analysed by western blotting, and quantitative densitometry of digitalised blots was performed using the Image $\mathrm{J}$ program (NIH) [26]. The primary antibodies used were against JAK2, p-STAT5, STAT5 (Cell Signaling, Danvers, MA, USA), BCLXL (Santa Cruz Biotechnology, Santa Cruz, CA, USA), cyclinD2 (Neomarkers, Fremont, CA, USA) and tubulin (CalBiochem/EMD Biosciences, Gibbstown, NJ, USA).

Statistical analysis The data are expressed as the mean \pm SE. Statistical significance considered at $p \leq 0.05$ was determined by unpaired two-tailed Student's $t$ test.

\section{Results}

Lactogens induce Prlr expression in beta cells under glucolipotoxic (GLT) conditions It has been shown that lactogens induce Prlr expression in islets under basal conditions [35]. To determine whether lactogens can induce Prlr expression in beta cells under conditions of GLT, islets from wild-type and RIP-mPll transgenic mice, which express Pll in their beta cells, were cultured in control or GLT media for $48 \mathrm{~h}$ and, subsequently, Prlr mRNA was quantified (Fig. 1a). As
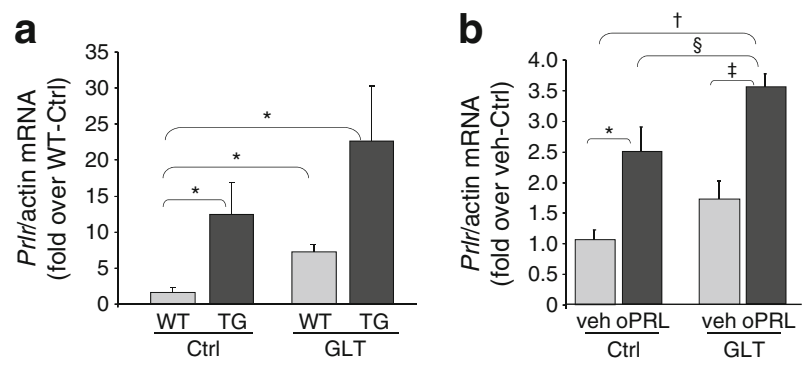

Fig. 1 Prlr expression in rodent beta cells under GLT conditions. Prlr mRNA expression by real time PCR (a) in islets from 3-6-month-old RIP- $m P l 1$ transgenic (TG) and wild-type (WT) littermates exposed to $25 \mathrm{mmol} / \mathrm{l}$ glucose and $0.5 \mathrm{mmol} / \mathrm{l}$ palmitate (GLT) or $5.5 \mathrm{mmol} / \mathrm{l}$ glucose and $0.5 \%$ BSA (Ctrl) for $48 \mathrm{~h}\left(n=3-4\right.$ mice/group); ${ }^{*} p<0.05$ vs. WT control; and (b) in vehicle (veh)- or oPRL-treated INS-1 cells exposed to $0.5 \mathrm{mmol} / 1$ palmitate (GLT) or $0.5 \% \mathrm{BSA}$ (Ctrl) for $12 \mathrm{~h}$ ( $n=6 /$ group); ${ }^{*} p<0.02,{ }^{\dagger} p<0.00001 \mathrm{veh} / \mathrm{Ctrl}$ vs. oPRL/Ctrl and oPRL/GLT, respectively; ${ }^{\ddagger} p<0.001 \mathrm{veh} / \mathrm{GLT}$ vs. oPRL/GLT; and ${ }^{\S} p<0.05$ oPRL/Ctrl vs. oPRL/ GLT groups. PCR cycles were compared with actin, used as an internal control

expected, there was an increase in Prlr mRNA in transgenic vs. wild-type islets under basal conditions. GLT also induced an increase in Prlr mRNA in wild-type islets (Fig. 1a). Importantly, the lactogen-induced increase in Prlr expression was maintained even after GLT treatment (Fig. 1a). To verify if this was true specifically in beta cells, we examined Prlr mRNA expression in INS-1 cells treated with or without palmitate and oPRL. Prlr expression was significantly increased not only with oPRL, but also with combined treatment with palmitate and oPRL (Fig. 1b), suggesting that lactogen signalling is likely to play a role in GLT-induced beta cell death.

Lactogens protect rodent beta cells against GLT-mediated cell death The known protective effect of lactogens against other cell death inducers such as STZ and glucocorticoids [25-27], and the increase in Prlr expression by lactogens under GLT conditions (Fig. 1), led us to postulate that lactogens will also protect beta cells against GLT-induced cell death. To examine this, islet cells from wild-type and RIP-mPll transgenic mice were cultured under GLT conditions for 24-36 h and beta cell death was assayed by insulin, TUNEL and DAPI co-staining (Fig. 2a). GLT induced a significant increase in beta cell death in wild-type islets compared with control conditions $(6.7 \pm 1.7 \%$ vs. $2.5 \pm 0.6 \%$, respectively; Fig. 2 b). However, lactogen expression in the beta cells of transgenic islets resulted in a complete and significant inhibition of beta cell death under GLT conditions $(2.7 \pm 0.4 \%)$ compared with wild-type islet cells (Fig. 2b). To understand the mechanism through which lactogens protect beta cells against GLT, we turned to INS-1 cells. We examined whether acute treatment with oPRL peptide, instead of chronic production of PL in beta cells, as in the transgenic islets, will protect INS-1 cells against two 
different concentrations of palmitate, measuring cell death by cleaved caspase-3 staining (Fig. 2c). There was a significant 15-21-fold increase in cell death in INS-1 cells cultured in the presence of either 0.25 or $0.5 \mathrm{mmol} / 1$ palmitate compared with control INS-1 cells (Fig. 2d). Treatment with $200 \mathrm{ng} / \mathrm{ml}$ of oPRL significantly reduced cell death by $35 \%$ (at $0.25 \mathrm{mmol} / 1$ palmitate) and $59 \%$ (at $0.5 \mathrm{mmol} /$ 1 palmitate) compared with vehicle-treated cells, although a

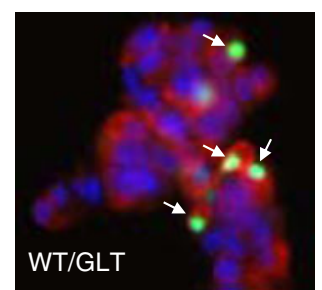

TUNEL; Insulin; DAPI

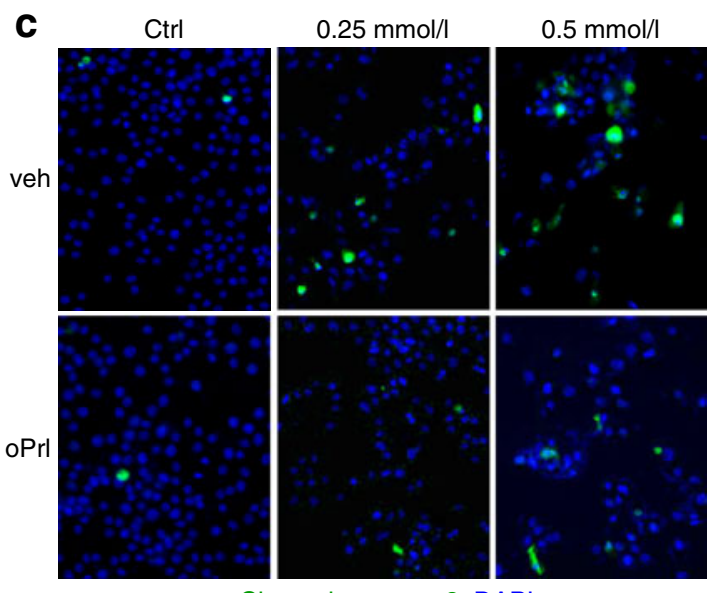

C

Cleaved caspase-3; DAPI b

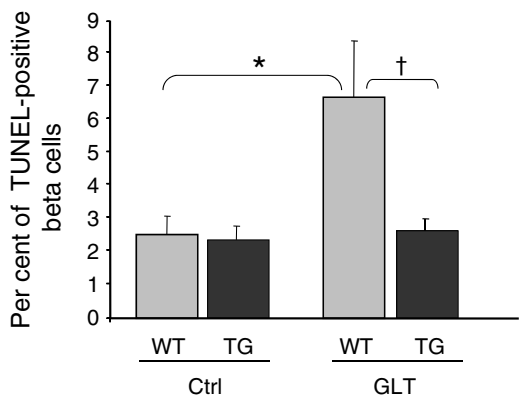

d

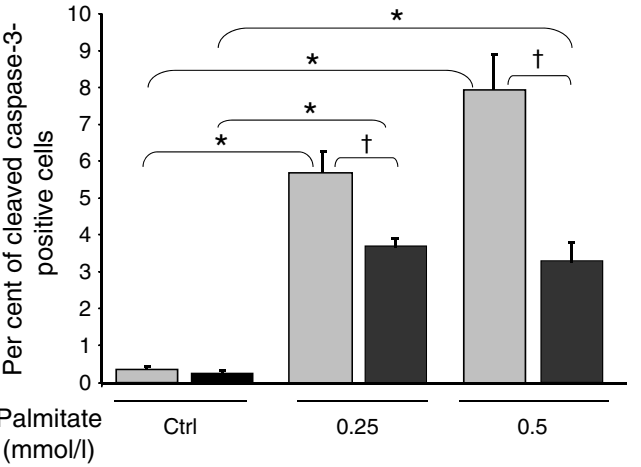

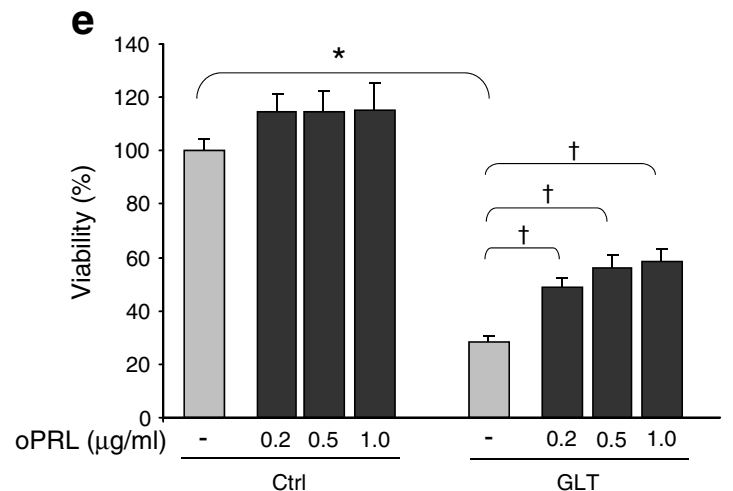

Fig. 2 Lactogens protect rodent beta cells against GLT-induced cell death. a Islet cell cultures from wild-type (WT) and RIP- $m P l 1$ transgenic (TG) mice treated with GLT for 24-36 h were stained for insulin (red), TUNEL (green) and DAPI (blue), with TUNEL-positive beta cells marked by arrows. b Quantification of the percentage of TUNELpositive beta cells in WT and TG islet cell cultures under Ctrl and GLT conditions $(n=8-11 /$ group, four independent experiments carried out in duplicate or triplicate, counting $1,140 \pm 186$ beta cells/condition); ${ }^{*} p<0.05$ WT-Ctrl vs. WT-GLT, and ${ }^{\dagger} p<0.05$ WT-GLT vs. TG-GLT. c INS-1 cells treated with vehicle (veh) or $200 \mathrm{ng} / \mathrm{ml}$ of oPRL in the absence (Ctrl) or presence of 0.25 or $0.5 \mathrm{mmol} / 1$ palmitate for $12 \mathrm{~h}$ were stained for cleaved caspase-3 (green) and DAPI (blue). d Quantification of the percentage of cleaved caspase-3-positive cells in vehicle-treated (grey bars) and oPRL-treated (black bars) INS-1 cells exposed to 0.25 or $0.5 \mathrm{mmol} / 1$ or no (Ctrl) palmitate $(n=14 /$ group, five independent experiments carried out in duplicate or triplicate, counting $4,042 \pm 336$ cells/condition); ${ }^{*} p \leq 0.0001$ vs. corresponding groups in the Ctrl treatment, and ${ }^{\dagger} p \leq 0.01 \mathrm{oPRL}-\mathrm{vs}$. vehicle-treated cells under the same conditions. e Per cent cell viability measured by the MTT assay in INS-1 cells treated with vehicle (grey bars) or three different concentrations $(0.2,0.5$ or $1.0 \mu \mathrm{g} / \mathrm{ml})$ of oPRL (black bars) in the absence (Ctrl) or presence of $0.5 \mathrm{mmol} / 1$ palmitate (GLT) for $12 \mathrm{~h}$; ${ }^{*} p \leq 0.05$ veh-Ctrl vs. veh-GLT cells; and ${ }^{\dagger} p \leq 0.05$ oPRL-treated vs. vehicle-treated GLT ( $n=3$ experiments in triplicate) 
it did not completely obliterate GLT-induced cell death (Fig. 2d). Treatment with higher doses of oPRL (500$1,000 \mathrm{ng} / \mathrm{ml}$ ) did not further improve cell survival against GLT-induced cell death compared with $200 \mathrm{ng} / \mathrm{ml}$ of oPRL, as measured by the MTT assay (Fig. 2e). Thus, lactogens, either endogenously produced or, upon acute treatment, significantly ameliorate GLT-induced rodent beta cell death.

JAK2 mediates the pro-survival effect of lactogens against GLT-induced cell death in rodent beta cells Lactogens activate multiple signalling pathways, including the JAK2/ STAT5 pathway, known to induce proliferative and prosurvival effects in multiple cell types [36, 37], including the beta cell $[17,26]$. In this study we wanted to determine whether JAK2 mediates the pro-survival effects of lactogens against GLT in rodent beta cells. To examine this, we used AG490, a pharmacological inhibitor of JAK2. INS-1 cells treated with AG490, or with the solvent DMSO, or left untreated as controls, were cultured in the presence or absence of $0.5 \mathrm{mmol} / 1$ palmitate and oPRL for $12-16 \mathrm{~h}$, and two different assays were used to detect cell death. oPRL significantly improved cell viability, assessed by the MTT assay (Fig. 3a), under GLT conditions, compared with vehicle-treated cells in untreated $(31.9 \pm 3.7 \%$ vs. $9.3 \pm$ $1.1 \%$, respectively) and DMSO-treated $(30.2 \pm 2.7 \%$ vs. $12.1 \pm 1.8 \%$, respectively) cells. However, in the presence of AG490 the protective effect of oPRL was significantly and completely lost $(7.9 \pm 1.2 \%$ vs. $8.4 \pm 0.7 \%$, respectively; Fig. 3a). Similar findings were obtained with the cleaved caspase- 3 assay, in that oPRL significantly reduced cell death under GLT conditions compared with vehicle-treated cells in untreated and DMSO-treated, but not in the AG490treated, cells (Fig. 3b), suggesting the importance of JAK2 in mediating this effect.

Since the inhibitor may have non-specific effects, we used a second approach in which we downregulated Jak2 expression in INS-1 cells using a Jak2-specific siRNA. There was $\sim 55 \%$ reduction in the level of JAK2 relative to control scrambled-siRNA-transfected cells as assessed by western blot (Fig. 4a). Importantly, as shown previously [26], Jak2-siRNA-transfection led to a reduction in oPRLinduced activation of p-STAT5 signalling (Fig. 4a). Cell viability assessed by the MTT assay (Fig. 4b) was significantly improved by oPRL $(58.3 \pm 3.5 \%)$ compared with vehicle-treated cells $(34.3 \pm 1.8 \%)$ in the presence of GLT in scrambled-siRNA-transfected cells. However, in Jak2siRNA-transfected cells the protective effect of oPRL against GLT-induced cell death was lost, with no difference in cell viability between vehicle- and oPRL-treated cells $(48.0 \pm 4.3 \%$ vs. $48.5 \pm 6.1 \%$, respectively; Fig. $4 b)$. The cleaved caspase- 3 assay also showed a significant reduction in GLT-induced cell death with oPRL in scrambled-siRNAtransfected cells, but not in Jak2-siRNA-transfected cells
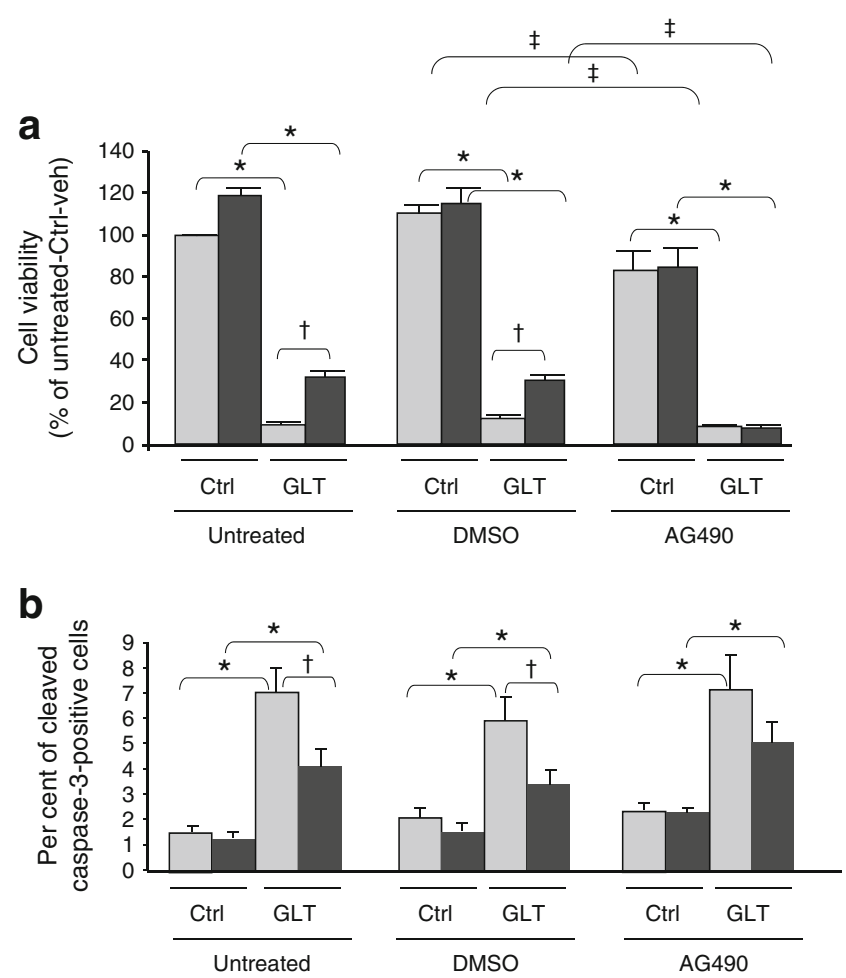

Fig. 3 Effect of JAK2 inhibitor on the pro-survival effect of lactogens in INS-1 cells against GLT-induced cell death. INS- 1 cells untreated or treated with DMSO or AG490, in the presence of $0.5 \%$ BSA (Ctrl) or $0.5 \mathrm{mmol} / 1$ palmitate (GLT), with vehicle (veh; grey bars) or oPRL (black bars) for $12 \mathrm{~h}$ were assessed (a) by the MTT assay for cell viability with untreated-Ctrl-veh group as $100 \%$. ${ }^{*} p<0.001$ corresponding GLT vs. Ctrl cells of the same treatment group; ${ }^{\dagger} p<0.01$ oPRL- vs. vehicle-treated GLT cells of the same treatment group; ${ }^{\sharp} p<0.05$ corresponding cells in the DMSO- vs. AG490-treated group ( $n=4-6$ experiments in triplicate); and (b) by cleaved caspase- 3 staining to measure per cent cell death. ${ }^{*} p \leq 0.02$ corresponding GLT vs. Ctrl cells of the same treatment group; ${ }^{\dagger} p \leq 0.05$ oPRL- vs. vehicle-treated GLT cells of the same treatment group $(n=4$ experiments in duplicate $)$

(Fig. 4c), further emphasising the importance of the JAK2 pathway in this process.

STAT5 activation is required for the pro-survival effect of lactogens against GLT-induced cell death in rodent beta cells It is well established that p-STAT5 is activated downstream of JAK2 by lactogens in beta cells [17, 26]. We next examined whether lactogens activate p-STAT5 in beta cells even under GLT conditions. INS-1 cells were cultured in the presence or absence of $0.5 \mathrm{mmol} / \mathrm{l}$ palmitate and oPRL for 12-16 h, and p-STAT5 activation was analysed by western blot (Fig. 5a). Quantitative analysis shows a clear and significant increase in p-STAT5 activation by oPRL not only under control conditions but also under GLT conditions (Fig. 5a). To assess the role of p-STAT5 activation in the pro-survival effect of PRL, we used a dominant negative mutant of Stat5 (DNStat5) that inhibits both STAT5a and STAT5b action [33]. The DNStat5 mutant blocked the 

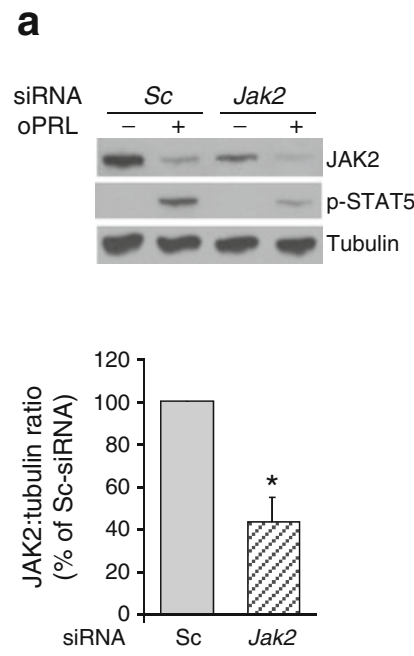

b
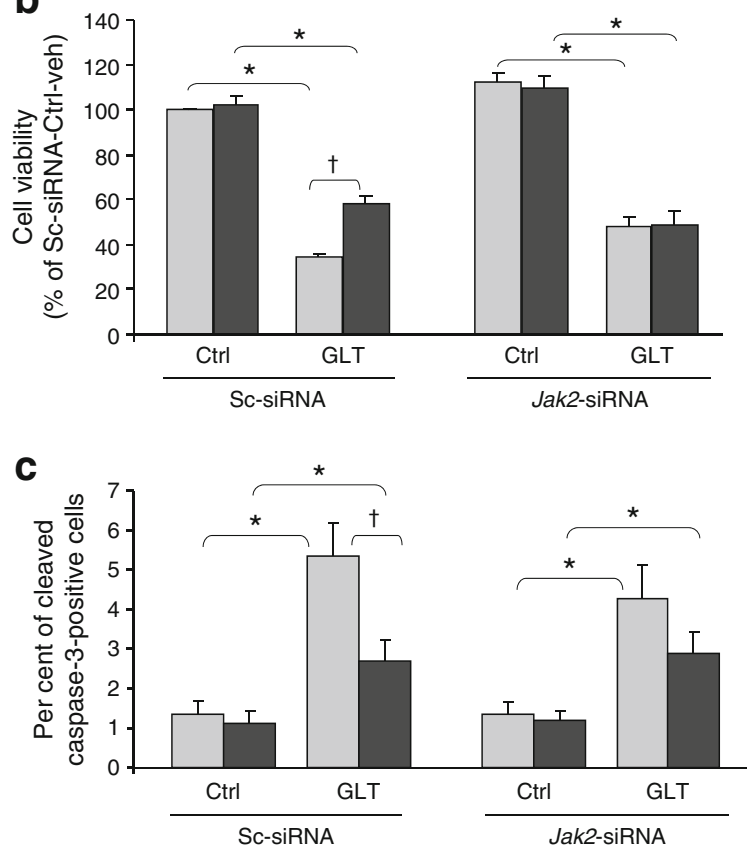

Fig. 4 Effect of Jak2 siRNA on the protective effect of lactogens against GLT-induced cell death in INS-1 cells. a Representative western blot analysis of INS-1 cells transfected with scrambled (sc) or Jak2specific (Jak2) siRNA, treated with $(+)$ or without $(-)$ oPRL, using JAK2, p-STAT5 and tubulin antibodies. Quantification of the JAK2/ tubulin ratio in the western blots shows $\sim 55 \%$ reduction in JAK2 levels in Jak2 siRNA relative to sc-siRNA-transfected INS-1 cells ${ }^{*} p<0.01$ $(n=5)$. Jak2 siRNA- or sc-siRNA-transfected INS-1 cells treated with vehicle (grey bars) or oPRL (black bars), under Ctrl or GLT conditions, were assessed for (b) cell viability by MTT assay; viability of scsiRNA-Ctrl-veh-treated INS-1 cells was taken as $100 \% ;{ }^{*} p \leq 0.0001$ corresponding GLT vs. Ctrl cells of the same treatment group; ${ }^{\dagger} p \leq$ $0.001 \mathrm{oPRL}-\mathrm{vs}$. vehicle-treated GLT cells of the same treatment group ( $n=5$ in triplicate); and (c) cell death by cleaved caspase- 3 staining; ${ }_{p}^{*}<0.05$ corresponding GLT vs. Ctrl cells of the same treatment group; $p \leq 0.02$ oPRL- vs. vehicle-treated GLT cells of the same treatment group ( $n=7$ experiments) induction of cyclinD2 by oPRL, a known PRL target gene activated by STAT5 [22], confirming the functional effectiveness of the DNStat5 mutant (Fig. 5b). INS-1 cells either uninfected or transduced with Adv-DNStat5 or control (Adv-Ctrl), were treated with or without GLT and oPRL, and cell death measured by two different assays. Uninfected and Adv-Ctrl-transduced cells behaved similarly in that oPRL significantly enhanced cell viability measured by the MTT assay against GLT in both conditions $(67.2 \pm 8.4 \%$ and $55.8 \pm 4.0 \%$, respectively), compared with vehicle-treated cells in GLT $(35.8 \pm 4.4 \%$ and $32.9 \pm 5.4 \%$, respectively; Fig. 5c). However, upon transduction with Adv-DNStat5, oPRL lost its protective effect against GLT. The viability of the vehicle-treated and oPRL-treated INS-1 cells was similar $(17.2 \pm 1.7 \%$ and $12.4 \pm 1.6 \%$, respectively; Fig. 5c). The essential role of STAT5 activation was further confirmed with the cleaved caspase- 3 assay, which showed a significant reduction in GLT-induced cell death with oPRL in Adv-Ctrl but not Adv-DNStat5-transduced cells (Fig. 5d).

Finally, to examine if the STAT5 pathway mediates the prosurvival effect of lactogens in primary rodent beta cells, islet cell cultures from wild-type and RIP-mPll transgenic mice were transduced with either Adv-Ctrl or Adv-DNStat5, cultured in control or GLT conditions for 24-36 h, and cell death measured by insulin, TUNEL and DAPI co-staining. As expected, quantification of TUNEL-positive beta cells under GLT conditions shows a significant decrease in cell death in Adv-Ctrl-transduced RIP-mPll transgenic islets $(1.1 \pm 0.1 \%)$ vs. wild-type islets $(2.0 \pm 0.2 \%)$. However, when islet cells were transduced with Adv-DNStat5, transgenic islets no longer had a survival advantage against GLT-induced beta cell death compared with wild-type islets $(1.7 \pm 0.03 \%$ vs. $1.7 \pm$ $0.3 \%$, respectively; Fig. 5e). This demonstrates that STAT5 activation is required for lactogens to protect primary rodent beta cells against GLT-induced cell death.

Lactogen-induced anti-apoptotic BCLXL, is required for its pro-survival effect against GLT-mediated cell death in rodent beta cells The anti-apoptotic member of the BCL family of molecules, BCLXL, is a known transcriptional target of lactogens and STAT5 activation in many cell types [15, 26]. Further, we have shown that BCLXL protein is upregulated in INS-1 cells in response to PRL [26]. To determine the role of BCLXL in the pro-survival effect of lactogens against GLT-mediated beta cell death, BCLXL levels were significantly repressed in INS-1 cells transfected with Bclxl- 


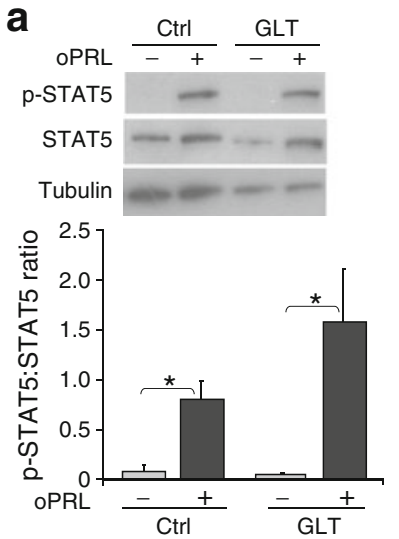

b
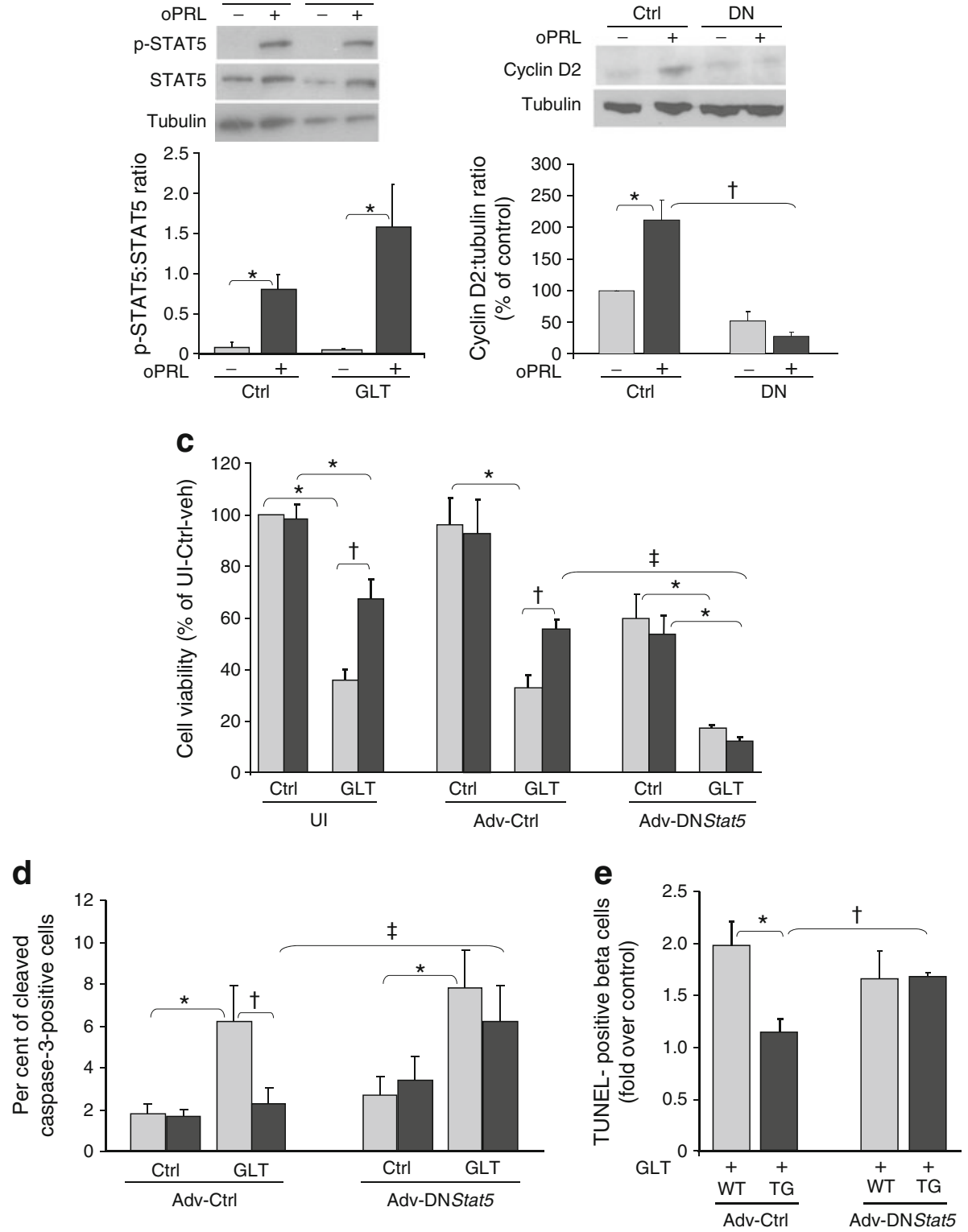

Fig. 5 Lactogen-mediated STAT5 activation is required to enhance beta cell survival against GLT-induced cell death in INS-1 cells and primary rodent beta cells. a Representative western blot of INS-1 cells \pm oPRL under Ctrl or GLT conditions, analysing production of p-STAT5, STAT5 and tubulin. Quantification of the p-STAT5/STAT5 ratio, with vehicle-treated (grey bars) Ctrl cells as $100 \%$, shows that oPRL (black bars) treatment significantly increases this ratio under $\mathrm{Ctrl}$ and GLT conditions; ${ }^{*} p<0.05$ vs. vehicle-treated cells in the same treatment group $(n=4)$. b Representative western blot of cyclin D2 and tubulin expression and quantification of the cyclin D2/tubulin ratio in INS-1 cells transfected with Adv-Ctrl (Ctrl) or Adv-DNStat5 (DN) with vehicle- (grey bars) or oPRL- (black bars) treatment, relative to ctrl-vehicle-treated cells as $100 ;{ }^{*} p \leq 0.05$ oPRL- vs. vehicle-treated Ctrl cells; ${ }^{\dagger} p \leq 0.05$ oPRL-treated Ctrl- vs. DN-transduced cells $(n=$ 3). Uninfected (UI), Adv-Ctrl, or Adv-DNStat5-transduced INS-1 cells treated with vehicle (grey bars) or oPRL (black bars) under Ctrl or GLT conditions were assessed for (c) cell viability measured by the MTT assay with UI-Ctrl-veh-treated INS-1 cells as $100 \% ;{ }^{*} p \leq 0.05$ corresponding GLT vs. Ctrl cells of the same treatment group; ${ }^{\dagger} p<0.05$ oPRL- vs. vehicle-treated GLT cells of the same treatment group; and ${ }^{\star} p<0.005$ oPRL-treated GLT cells of the Adv-Ctrl vs. Adv-DNStat 5 group ( $n=3$ in triplicate); and (d) cell death by cleaved caspase-3 staining; ${ }^{*} p \leq 0.02$ corresponding GLT vs. Ctrl cells of the same treatment group; ${ }^{\dagger} p<0.05$ oPRL- vs. vehicle-treated GLT cells of the same treatment group; and ${ }^{\star} p<0.05$ oPRL-treated GLT cells of the Adv-Ctrl vs. Adv-DNStat5 group ( $n=4$ experiments in duplicate). e Quantification of TUNEL-positive beta cells in wild-type (WT) and RIP-mPll transgenic (TG) mouse islet cell cultures transduced with Adv-Ctrl or Adv-DNStat5 under GLT (shown in figure) and control non-GLT (not shown) conditions. Beta cell death is normalised to WT Adv-Ctrl-transduced cells under Ctrl non-GLT conditions (not shown) which had a basal beta cell death rate of $3.3 \pm 0.3 \%$. ${ }^{*} p<0.05$ WT vs. TG Adv-Ctrl-transduced cells; ${ }^{\dagger} p<0.05$ TG Adv-Ctrl vs. AdvDNStat5-transduced cells $(n=3$ experiments in duplicate, counting $2,521 \pm 426$ beta cells/condition) 
specific siRNA compared with control-scrambled-siRNA (Fig. 6a). In scrambled-siRNA-transfected cells, oPRL significantly improved cell viability $(58.3 \pm 3.5 \%)$ in the presence of GLT, as assessed by the MTT assay, compared with vehicle-treated cells (34.3 $\pm 1.8 \%$; Fig. 6b). As expected, BCLXL downregulation significantly lowered cell viability in control and palmitate-treated cells (Fig. 6b). Importantly, the protective effect of oPRL against GLT-induced cell death observed in scrambled-siRNA-transfected cells was completely lost in the Bclxl-siRNA-transfected cells, with no difference in cell viability between vehicle- and oPRLtreated cells $(21.0 \pm 1.8 \%$ vs. $20.8 \pm 2.5 \%$, respectively; Fig. 6b). Cleaved caspase-3 staining also showed a significant decrease in GLT-induced cell death with oPRL in scrambled siRNA-transfected but not Bclxl siRNA-transfected cells (Fig. 6c), indicating the importance of BCLXL in mediating the protective effect of lactogens against GLT in INS-1 cells.

We next examined whether BCLXL is important for the pro-survival effect of lactogens in primary rodent beta cells against GLT. We have previously shown that RIP-mPll transgenic islets have significantly enhanced levels of BCLXL compared with normal islets [26]. Here, we asked if the increase in BCLXL production induced by lactogens was at the transcriptional level, and furthermore, whether the lactogen-induced increase in BCLXL was maintained in response to GLT. Bclxl mRNA was analysed by real time PCR from wild-type and RIP-mPll transgenic mouse islets kept under control or GLT conditions for $48 \mathrm{~h}$. Indeed, lactogens significantly increased Bclxl mRNA by $\sim$ five-fold under control conditions (Fig. 7a), indicating an effect at the transcriptional level. Furthermore, $B c l x l$ mRNA was also significantly increased under GLT conditions and, importantly, there was a further significant increase in Bclxl expression with lactogen treatment under GLT conditions (Fig. 7a). To determine whether $B c l x l$ is important in the lactogen-mediated pro-survival effect against GLT in rodent beta cells, we used mouse islets from $B c l x l$ floxed mice and transduced these cell cultures with Adv-Cre recombinase, to delete the Bclxl gene, or with Adv-Ctrl. Co-staining for $\mathrm{CRE}$, insulin and DAPI clearly shows CRE protein in the nucleus of beta cells of Adv-Cre-transduced cells and not in Adv-Ctrl-transduced cells (Fig. 7b). To assess GLT-induced beta cell death, these cells were cultured in GLT media for 24-36 $\mathrm{h}$ in the presence or absence of oPRL and assayed by TUNEL, insulin and DAPI co-staining. There was a significant increase in beta cell death in Adv-Ctrl-transduced cells a
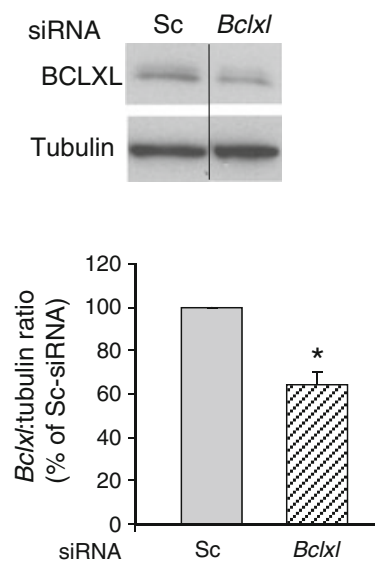

b

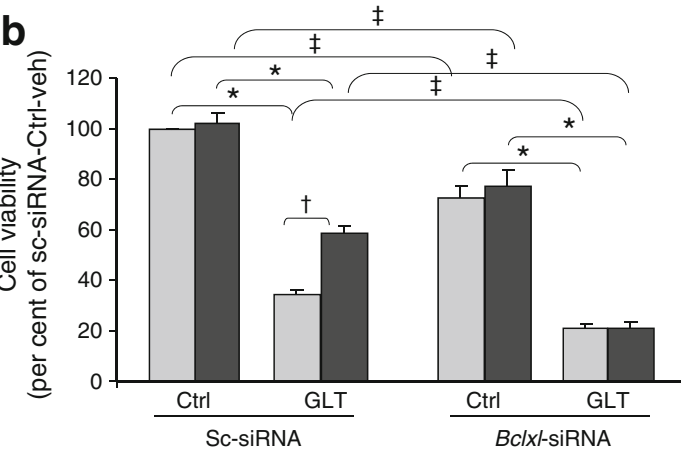

C

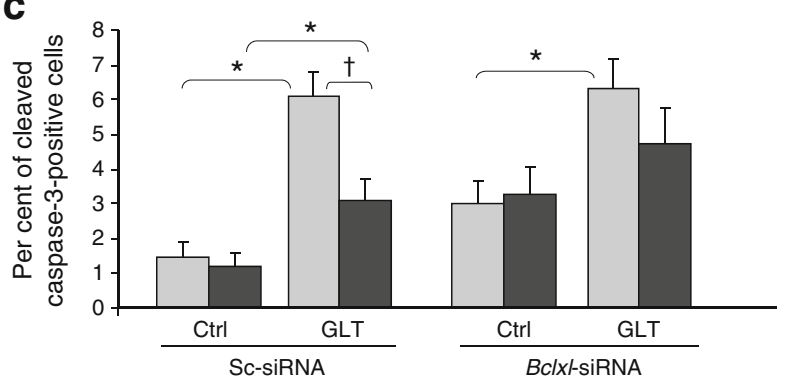

Fig. 6 PRL protects INS-1 cells against GLT-induced cell death through the anti-apoptotic BCLXL protein. a Representative western blot analysis of INS-1 cells transfected with scrambled (sc) or Bclxlspecific $(B c l x l)$ siRNA, using BCLXL and tubulin antibodies. The line separates two non-contiguous regions of the same western blot. Quantification of the BCLXL/tubulin ratio in the western blots shows a significant reduction in BCLXL production in $B c l x l$ siRNA- relative to sc-siRNA-transfected INS-1 cells ${ }^{*} p<0.05(n=5)$. INS-1 cells transfected with sc-siRNA or $B c l x l$ siRNA, treated with vehicle (grey bars) or oPRL (black bars), under Ctrl or GLT conditions, were assessed for (b) cell viability measured by the MTT assay, with sc-siRNA-Ctrl-vehtreated INS- 1 cells taken as $100 \% ;{ }^{*} p<0.0005$ corresponding GLT vs. Ctrl cells of the same treatment group; ${ }^{\dagger} p<0.001$ oPRL- vs. vehicletreated GLT cells of the same siRNA transfection; ${ }^{\star} p<0.02$ corresponding groups in sc-siRNA vs. $B c l x l$ siRNA-transfected cells ( $n=5$ in triplicate); and (c) cell death by cleaved caspase- 3 staining; ${ }^{*} p$ $<0.05$ corresponding GLT vs. Ctrl cells of the same treatment group; ${ }^{\dagger} p<0.02$ oPRL- vs. vehicle-treated GLT cells of the same treatment group ( $n=5$ experiments in duplicate) 
a

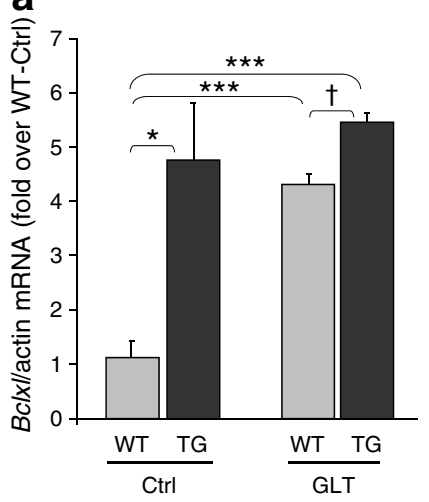

Fig. 7 Lactogens mediate their pro-survival effect against GLTinduced cell death through BCLXL in primary rodent beta cells. a Quantification of $B c l x l$ mRNA expression by real time PCR in islets from RIP- $m P l 1$ transgenic (TG) mice and wild-type (WT) littermates exposed to GLT or Ctrl conditions for $48 \mathrm{~h}$ ( $n=4 /$ group). PCR cycles were compared with actin, used as an internal control; ${ }^{*} p<0.05$ and ${ }^{* * * *} p<0.0005$ vs. WT islets under Ctrl conditions; ${ }^{\dagger} p<0.01$ vs. WT islets under GLT conditions. b Mouse islet cell cultures transduced with Adv-Cre or Adv-Ctrl co-stained for Cre (red), insulin (green) and DAPI (blue) show Cre staining in the nuclei of Adv-Cre-transduced but

upon GLT treatment $(3.3 \pm 0.4 \%)$ which was significantly reduced with oPRL $(1.9 \pm 0.4 \%$; Fig. $7 \mathrm{c})$. However, in Adv-Cre-transduced cells, GLT-induced beta cell death $(2.4 \pm 0.3 \%)$ is not ameliorated in the presence of oPRL (2.2 $\pm 0.4 \%$; Fig. $7 \mathrm{c})$, demonstrating the importance of BCLXL in mediating the pro-survival effect of PRL against GLT-induced beta cell death in primary rodent beta cells.

Lactogens improve human beta cell survival against GLT-induced cell death through activation of the STAT5 pathway Following our findings in rodent beta cells, we hypothesised that lactogens are likely to protect human beta cells against GLT-induced cell death. Human islet cells were cultured for 24-36 h under GLT or control conditions in the presence or absence of two different human lactogenic peptides, hPRL or hPL, and beta cell death was measured by TUNEL, insulin and DAPI co-staining (Fig. 8a). The significant threefold increase in human beta cell death observed with GLT in vehicle-treated cells was significantly decreased by either hPRL or hPL treatment (Fig. 8b). Following our findings in rodent beta cells, we examined whether BCLXL production is upregulated by lactogens in human islets. Western blot analysis of human islets treated with $\mathrm{hPRL}$ for $24 \mathrm{~h}$ did not show a significant increase in the ratio of BCLXL:actin compared with vehicle-treated human islets ( $0.88 \pm 0.2$ vs. $0.67 \pm 0.3$, respectively). PRL is known to activate p-STAT5 in human islets [28] and, using our findings in rodent islets (Fig. 5), we hypothesised that STAT5 activation is likely to be involved in the prosurvival effects of lactogens in human beta cells. Beta cell

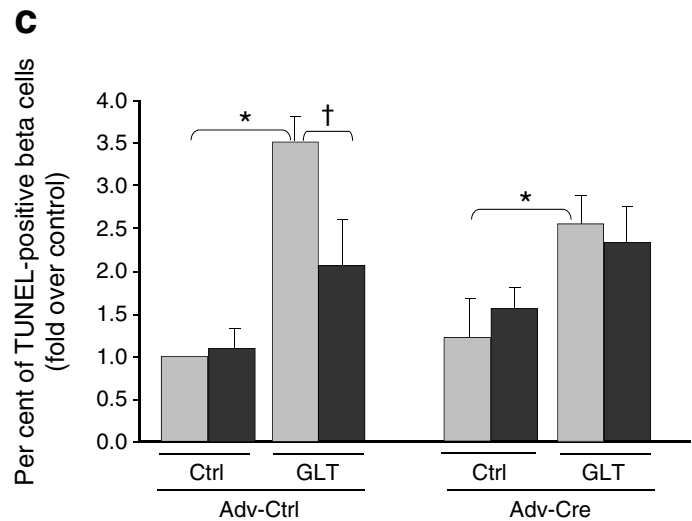

not Adv-Ctrl-transduced beta cells. $\mathbf{c}$ Quantification of the percentage of TUNEL-positive beta cells in $B c l x l$ floxed mouse islet cell cultures transduced with Adv-Ctrl or Adv-Cre under control non-GLT and GLT conditions treated with vehicle (grey bars) or oPRL (black bars). Beta cell death is normalised to vehicle-treated Adv-Ctrl-transduced cells under Ctrl non-GLT conditions, which had a basal beta cell death rate of $2.5 \pm 0.5 \% ;{ }^{*} p \leq 0.05$ corresponding GLT vs. Ctrl cells of the same treatment group; ${ }^{\dagger} p \leq 0.05$ oPRL- vs. vehicle-treated Adv-Ctrl-transduced GLT groups $(n=5$ experiments in duplicate, counting $1,729 \pm 202$ beta cells/condition)

death was quantified in human islet cells transduced with either Adv-Ctrl or Adv-DNStat5, and cultured in control or GLT conditions in the presence or absence of hPRL peptide for $24-36 \mathrm{~h}$ (Fig. 8c). GLT induced a significant $60 \%$ increase in beta cell death in vehicle-treated Adv-Ctrltransduced cells that was significantly reduced in the presence of hPRL (Fig. 8c). In the Adv-DNStat5-transduced vehicle-treated cells, GLT induced a similar increase in human beta cell death as in Adv-Ctrl-transduced cells; however, treatment with hPRL did not protect the Adv-DNStat5-transduced human beta cells from GLT-induced cell death (Fig. 8c). Thus, lactogens protect human beta cells against GLT-induced cell death, and this is also mediated through activation of the STAT5 pathway.

\section{Discussion}

Beta cell death plays an important role in the loss of functional beta cell mass that occurs not only in type 1 but also in type 2 diabetes. An increase in beta cell death, probably mediated by GLT, has been observed in several animal models, as well as in patients with type 2 diabetes [1-14, 23]. This study is the first to demonstrate a direct protective effect of the lactogenic hormones, PRL and PL, on beta cell survival against GLT-induced cell death in both rodent and human beta cells. However, exogenous addition of lactogenic peptides did not confer complete protection against GLT-mediated beta cell death. Previously, we found that lactogens can protect rodent beta cells against other cell 
a

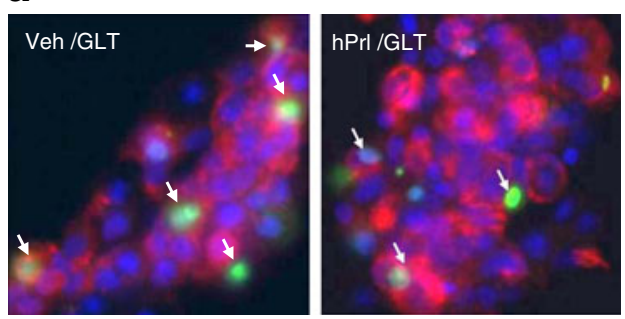

TUNEL; Insulin; DAPI

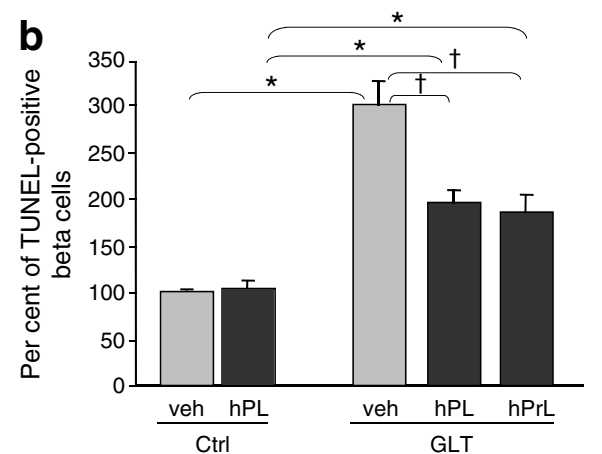

Fig. 8 Lactogens protect human beta cells against GLT-induced cell death through the JAK2/STAT5 signalling pathway. a Human islet cell cultures treated with vehicle (veh) or hPRL under GLT conditions for 24-36 $\mathrm{h}$ were stained for insulin (red), TUNEL (green) and DAPI (blue), with TUNEL-positive beta cells marked by arrows. b Quantification of TUNEL-positive beta cells in vehicle- (grey bars), hPRL- or hPL-treated (black bars) human islet cell cultures under Ctrl and GLT conditions. Beta cell death was normalised to $\mathrm{Ctrl} /$ vehicle-treated cells with a basal beta cell death rate of $2.0 \pm 0.4 \%,(n=4-5$ human islet preps at least in triplicate, counting $4,582 \pm 746$ beta cells/condition), ${ }^{*} p<0.02$ vs. corresponding group under $\mathrm{Ctrl}$ conditions; and ${ }^{\dagger} p<0.02$

death inducers including STZ and DEX [23-26]. Recent findings show that PRL also protects human beta cells against different cell death inducers, including cytokines, hydrogen peroxide and serum-starvation [28, 29]. Therefore, together, these studies clearly suggest that lactogens are prosurvival factors for the beta cell, in rodents and humans, against varied cell death inducers that are important in type 1 and 2 diabetes and islet transplantation.

Lactogens, through the PRL-R, activate many different intracellular signalling pathways in the beta cell [17, 22, 23, 26]. Here, we show that lactogens protect rodent beta cells against GLT through activation of the JAK2/STAT5 pathway, using complementary approaches, including a pharmacological inhibitor and siRNA against Jak2, and a DNStat5 mutant. This finding, together with our previous observation that the JAK2/STAT5 pathway also mediates the prosurvival effect of lactogens against DEX-induced rodent beta cell death [26], implies that this intracellular signalling pathway is a key mediator of the protective effect of lactogens in rodent beta cells in vitro. The role of the STAT5 pathway in the beta cell has been examined in vivo using two separate approaches. RIP-DNStat5 transgenic mice [38] and mice with Cre-lox elimination of Stat 5 in the beta cell and pancreas [39] display no major alterations in islet development or function under basal conditions. However, the loss of STAT5 signalling in RIP-DNStat5 mice had a negative impact in the setting of type 1 and 2 diabetes [38] and a mild effect on glucose tolerance with age in the pancreasspecific knockout mice [39], suggesting the requirement of this signalling pathway at least under stress-induced conditions in vivo.
hPL- and hPrL- vs. vehicle-treated group under GLT conditions. c Quantification of the percentage of TUNEL-positive beta cells in human islet cell cultures transduced with Adv-Ctrl or Adv-DNStat5 under GLT (shown in figure) and control non-GLT (not shown) conditions, treated with vehicle (grey bars) or hPRL (black bars). Beta cell death was normalised to vehicle-treated Adv-Ctrl-transduced cells under Ctrl non-GLT conditions (not shown) with a basal beta cell death rate of $3.6 \pm 0.6 \%$. ${ }^{*} p<0.02 \mathrm{hPL} / \mathrm{hPRL}-\mathrm{vs}$. vehicle-treated Adv-Ctrltransduced cells; ${ }^{\dagger} p<0.02 \mathrm{hPRL}-$ treated Adv-Ctrl vs. Adv-DNStat 5 transduced cells $(n=3$ experiments in duplicate, counting $11,004 \pm$ 1,229 beta cells/condition)

The activated STAT5 transcription factor induces expression of many target genes, including the anti-apoptotic BCL family member, $B c l x l$, in various cell types [40-42]. Here we show that lactogens induce $B c l x l$ mRNA expression in rodent beta cells, and that they can do so under GLT conditions. Furthermore, our data clearly indicate that increased BCLXL levels are required for the anti-apoptotic effect of lactogens against GLT-induced beta cell death, as demonstrated in INS-1 cells using Bclxl specific siRNAs, and in primary rodent beta cells using Cre-mediated deletion of the floxed Bclxl gene. We have previously shown that PRL-induced BCLXL is needed for its pro-survival effect against DEX-induced cell death in INS-1 cells [26]. The BCL family of proteins is a major regulator of the intrinsic mitochondrial cell death pathway [43]. Considering that both DEX and GLT mediate their toxic effects through the intrinsic cell death pathway [44, 45], it is not surprising that BCLXL, an anti-apoptotic member of the BCL family, is protective against both cell death inducers. Thus, BCLXL is an important, although not the sole, mediator of the prosurvival effects of lactogens in rodent beta cells.

Although lactogens obviously protect rodent beta cells, there is nothing known regarding their effect on human beta cell survival against GLT-induced cell death. This study clearly demonstrates that lactogens confer significant, although not complete, protection to human beta cells against GLT. Furthermore, using the DNStat 5 mutant we show that the PRL-induced anti-apoptotic effect is mediated through the STAT5 pathway in human beta cells, similarly to rodent beta cells. In this regard, two recent reports have found that PRL protects human beta cells against different cell death 
inducers $[28,29]$, and that treatment with a JAK2 pharmacological inhibitor abolishes the protective effect of PRL [28]. Using these findings, we can now categorise lactogens as pro-survival factors for human beta cells, and can designate the JAK2/STAT5 pathway as a key mediator of this effect in human beta cells. However, unlike in rodents, lactogens did not induce BCLXL production in human beta cells. This is corroborated in a recent study which also found that hPRL did not increase BCLXL levels in human islets, but instead increased the ratio of the anti- to pro-apoptotic proteins BCL2/BAX [28]. Both BCL2 and BCLXL are known downstream targets of STAT5 activation in other cell types [37]. Therefore, it is possible that in human islets lactogens may mediate their pro-survival effects through STAT5 induction of BCL2.

These studies, together with previous work, clearly demonstrate that the pro-survival nature of lactogens is mediated through the JAK2/STAT5 pathway in both rodent and human beta cells, thus identifying this pathway as a potential therapeutic target for diabetes. Interestingly, in this regard, studies have shown that there is an enhancement of residual beta cell function, an increase in C-peptide concentration and a significant decline in insulin requirement during pregnancy in patients with diabetes [46-48], suggesting that lactogen signalling, which is also upregulated during pregnancy, may be involved in this effect. Future studies will determine the effectiveness of lactogens in vivo in the pathophysiology of type 2 diabetes.

Acknowledgements We are grateful to L. Hennighausen (NIH/ NIDDK, Bethesda, MD, USA) for kindly providing us with the $B c l x l$ floxed mice; to H. Yamashita (Nagoya City University, Nagoya, Japan) for kindly providing us with the DN-Stat 5 cDNA; to L. Alonso, A.F. Stewart, N. Taesch, and D. Scott for their input and critical comments; to K. Williams and S. Valle for superb technical assistance; to $\mathrm{K}$. Takane for generation of the adenoviral constructs; and to the IIDP and JDRF basic science islet distribution programs for provision of human islets at a discounted cost.

Funding This work was supported by grants from the National Institutes of Health (DK078060 and DK072264) to R. C. Vasavada.

Duality of interest The authors declare that there is no duality of interest associated with this manuscript.

Author contribution $\mathrm{NGK}, \mathrm{AM}, \mathrm{CC}$ and $\mathrm{AO}$ analysed data and revised the manuscript; AGO was involved in the design of the study and revised the manuscript; RCV was responsible for the conception of the study and drafting the article. All authors approved the final version.

\section{References}

1. Nolan CJ, Damm P, Prentki M (2011) Type 2 diabetes across generations: from pathophysiology to prevention and management. Lancet 378:169-181
2. Cnop M (2008) Fatty acids and glucolipotoxicity in the pathogenesis of type 2 diabetes. Biochem Soc Trans 36:348-352

3. Poitout V, Robertson RP (2007) Glucolipotoxicity: fuel excess and $\beta$-cell dysfunction. Endocr Rev 29:351-366

4. Prentki M, Nolan CJ (2006) Islet beta cell failure in type 2 diabetes. J Clin Invest 116:1802-1812

5. Shafrir E, Ziv E, Mosthaf L (1999) Nutritionally induced insulin resistance and receptor defect leading to beta-cell failure in animal models. Ann N Y Acad Sci 892:223-246

6. Leiter EH, Coleman DL, Hummel KP (1981) The influence of genetic background on the expression of mutations at the diabetes locus in the mouse. III. Effect of $\mathrm{H}-2$ haplotype and sex. Diabetes 30:1029-1034

7. Matveyenko AV, Butler PC (2006) Islet amyloid polypeptide (IAPP) transgenic rodents as models for type 2 diabetes. ILAR J 47:225-233

8. Pick A, Clark J, Kubstrup C et al (1998) Role of apoptosis in failure of $\beta$-cell mass compensation for insulin resistance and $\beta$-cell defects in the male Zucker diabetic fatty rat. Diabetes 47:358364

9. Donath MY, Gross DJ, Cerasi E et al (1999) Hyperglycemia induced beta-cell apoptosis in pancreatic islets of Psammomys obesus during development of diabetes. Diabetes 48:738-744

10. Butler AE, Janson J, Bonner-Weir S et al (2003) Beta-cell deficit and increased beta-cell apoptosis in humans with type 2 diabetes. Diabetes 52:102-110

11. Sakuraba H, Mizukami H, Yagihashi N, Wada R, Hanyu C, Yagihashi S (2002) Reduced $\beta$-cell mass and expression of oxidative stress-related DNA damage in the islets of Japanese type II diabetic patients. Diabetologia 45:85-96

12. Shimabukuro M, Zhou YT, Levi M, Unger RH (1998) Fatty acidinduced beta cell apoptosis: a link between obesity and diabetes. Proc Natl Acad Sci USA 95:2498-2502

13. El-Assaad W, Buteau J, Peyot ML et al (2003) Saturated fatty acids synergize with elevated glucose to cause pancreatic beta-cell death. Endocrinology 144:4154-4163

14. Federici M, Hribal M, Perego L et al (2001) High glucose causes apoptosis in cultured human pancreatic islets of Langerhans: a potential role for regulation of specific Bcl family genes toward an apoptotic cell death program. Diabetes 50:1290-1301

15. Goffin V, Binart N, Clement-Lacroix P et al (1999) From the molecular biology of prolactin and its receptor to the lessons learned from knockout mice models. Genet Anal 15:189-201

16. Talamantes F (1990) Structure and regulation of secretion of mouse placental lactogens. Prog Clin Biol Res 342:81-85

17. Sorenson RL, Stout LE (1995) Prolactin receptors and JAK2 in islets of Langerhans: an immunohistochemical analysis. Endocrinology 136:4092-4098

18. Freemark M, Driscoll P, Maaskant R, Petryk A, Kelly PA (1997) Ontogenesis of prolactin receptors in the human fetus in early gestation. Implications for tissue differentiation and development. J Clin Invest 99:1107-1117

19. Freemark M, Avril I, Fleenor D et al (2002) Targeted deletion of the PRL receptor: effects on islet development, insulin production, and glucose tolerance. Endocrinology 143:1378-1385

20. Huang C, Snider F, Cross JC (2009) Prolactin receptor is required for normal glucose homeostasis and modulation of beta-cell mass during pregnancy. Endocrinology 150:1618-1626

21. Brelje TC, Scharp DW, Lacy PE et al (1993) Effect of homologous placental lactogens, prolactins, and growth hormones on islet B cell division and insulin secretion in rat, mouse, and human islets: implication for placental lactogen regulation of islet function during pregnancy. Endocrinology 132:879-887

22. Vasavada RC, Gonzalez-Pertusa JA, Fujinaka Y, Fiaschi-Taesch NM, Cozar I, Garcia-Ocaña A (2006) Growth factors and pancreatic beta cell proliferation. Int J Biochem Cell Biol 38:931-950 
23. Guthalu NK, Zhang XY, Williams K, Mozar A, Vasavada RC (2010) Growth factor mediated regulation of beta cell survival. Open Endocr J 4:80-95

24. Vasavada RC, Garcia-Ocana A, Zawalich WS et al (2000) Targeted expression of placental lactogen in the beta cells of transgenic mice results in beta cell proliferation, islet mass augmentation and hypoglycemia. J Biol Chem 275:15399-15406

25. Fujinaka Y, Sipula D, Garcia-Ocaña A, Vasavada RC (2004) Characterization of mice doubly transgenic for parathyroid hormone-related protein and murine placental lactogen: a novel role for placental lactogen in pancreatic beta cell survival. Diabetes 53:3120-3130

26. Fujinaka Y, Takane K, Yamashita H, Vasavada RC (2007) Lactogens promote beta cell survival through JAK2/STAT5 activation and Bcl-XL upregulation. J Biol Chem 282:30707-30717

27. Weinhaus AJ, Bhagroo NV, Brelje TC, Sorenson RL (2000) Dexamethasone counteracts the effect of prolactin on islet function: implications for islet regulation in late pregnancy. Endocrinology 141:1384-1393

28. Terra LF, Garay-Malpartida MH, Wailemann RA, Sogayar MC, Labriola L (2011) Recombinant human prolactin promotes human beta cell survival via inhibition of extrinsic and intrinsic apoptosis pathways. Diabetologia 54:1388-1397

29. Yamamoto T, Mita A, Ricordi C et al (2010) Prolactin supplementation to culture medium improves beta-cell survival. Transplantation 89:1328-1335

30. Wagner KU, Claudio E, Rucker EB 3rd et al (2000) Conditional deletion of the Bcl-x gene from erythroid cells results in hemolytic anemia and profound splenomegaly. Development 127:4949-4958

31. Vasavada RC, Wang L, Fujinaka Y et al (2007) Protein kinase C-zeta activation markedly enhances beta-cell proliferation: an essential role in growth factor mediated beta-cell mitogenesis. Diabetes 56:27322743

32. Cousin SP, Hügl SR, Wrede CE, Kajio H, Myers MG Jr, Rhodes CJ (2001) Free fatty acid-induced inhibition of glucose and insulinlike growth factor I-induced deoxyribonucleic acid synthesis in the pancreatic $\beta$-cell line INS-1. Endocrinology 142:229-240

33. Yamashita H, Iwase H, Toyama T, Fujii Y (2003) Naturally occurring dominant-negative Stat5 suppresses transcriptional activity of estrogen receptors and induces apoptosis in T47D breast cancer cells. Oncogene 22:1638-1652

34. Guthalu Kondegowda N, Joshi-Gokhale S, Harb G et al (2010) Parathyroid hormone-related protein enhances human $\beta$-cell proliferation and function with associated induction of cyclin-dependent kinase 2 and cyclin E expression. Diabetes 59:3131-3138
35. Møldrup A, Petersen ED, Nielsen JH (1993) Effects of sex and pregnancy hormones on growth hormone and prolactin receptor gene expression in insulin-producing cells. Endocrinology 133:1165-1172

36. Valentino L, Pierre J (2006) JAK/STAT signal transduction: regulators and implication in hematological malignancies. Biochem Pharmacol 71:713-721

37. Ferbeyre G, Moriggl R (2011) The role of Stat5 transcription factors as tumor suppressors or oncogenes. Biochim Biophys Acta 1815:104-114

38. Jackerott M, Møldrup A, Thams P et al (2006) STAT5 activity in pancreatic beta-cells influences the severity of diabetes in animal models of type 1 and 2 diabetes. Diabetes 55:2705-2712

39. Lee JY, Gavrilova O, Davani B, Na R, Robinson GW, Hennighausen L (2007) The transcription factors $S t a t 5 a / b$ are not required for islet development but modulate pancreatic beta-cell physiology upon aging. Biochim Biophys Acta 1773:1455-1461

40. Silva M, Benito A, Sanz C et al (1999) Erythropoietin can induce the expression of bcl-x(L) through Stat5 in erythropoietindependent progenitor cell lines. J Biol Chem 274:22165-22169

41. Dumon S, Santos SC, Debierre-Grockiego F et al (1999) IL-3 dependent regulation of Bcl-xL gene expression by STAT5 in a bone marrow derived cell line. Oncogene 18:4191-4199

42. Horita M, Andreu EJ, Benito A et al (2000) Blockade of the Bcr-Abl kinase activity induces apoptosis of chronic myelogenous leukemia cells by suppressing signal transducer and activator of transcription 5-dependent expression of Bcl-xL. J Exp Med 191:977-984

43. Lindsay J, Esposti MD, Gilmore AP (2011) Bcl-2 proteins and mitochondria-specificity in membrane targeting for death. Biochim Biophys Acta 1813:532-539

44. Druilhe A, Létuvé S, Pretolani M (2003) Glucocorticoid-induced apoptosis in human eosinophils: mechanisms of action. Apoptosis 8:481-495

45. Robertson R, Zhou H, Zhang T, Harmon JS (2007) Chronic oxidative stress as a mechanism for glucose toxicity of the beta cell in type 2 diabetes. Cell Biochem Biophys 48:139-146

46. Pirttiaho HI, Hartikainen-Sorri AL, Kaila JM, Puukka R (1986) Residual B cell function and glycaemic control in diabetic pregnancy. Horm Metab Res 18:250-252

47. Jovanovic L, Mills JI, Knopp RH et al (2001) Declining insulin requirement in the late first trimester of diabetic pregnancy. Diabetes Care 24:1130-1136

48. Nielsen LR, Rehfeld JF, Pedersen-Bjergaard U, Damm P, Mathiesen ER (2009) Pregnancy-induced rise in serum C-peptide concentrations in women with type 1 diabetes. Diabetes Care 32:1052-1057 